\title{
National Early Warning Score 2 (NEWS2) on admission predicts severe disease and in- hospital mortality from Covid-19 - a prospective cohort study
}

Marius Myrstad ${ }^{1,2^{*}}$ (D) Håkon Ihle-Hansen ${ }^{1,2}$, Anders Aune Tveita ${ }^{1,3}$, Elizabeth Lyster Andersen ${ }^{1,2}$, Ståle Nygård ${ }^{4,5}$, Arnljot Tveit ${ }^{2,6}$ and Trygve Berge ${ }^{1,2}$

\begin{abstract}
Background: There is a need for validated clinical risk scores to identify patients at risk of severe disease and to guide decision-making during the covid-19 pandemic. The National Early Warning Score 2 (NEWS2) is widely used in emergency medicine, but so far, no studies have evaluated its use in patients with covid-19. We aimed to study the performance of NEWS2 and compare commonly used clinical risk stratification tools at admission to predict risk of severe disease and in-hospital mortality in patients with covid-19.

Methods: This was a prospective cohort study in a public non-university general hospital in the Oslo area, Norway, including a cohort of all 66 patients hospitalised with confirmed SARS-CoV-2 infection from the start of the pandemic; 13 who died during hospital stay and 53 who were discharged alive. Data were collected consecutively from March 9th to April 27th 2020. The main outcome was the ability of the NEWS2 score and other clinical risk scores at emergency department admission to predict severe disease and in-hospital mortality in covid-19 patients. We calculated sensitivity and specificity with 95\% confidence intervals (Cls) for NEWS2 scores $\geq 5$ and $\geq 6$, quick Sequential Organ Failure Assessment (qSOFA) score $\geq 2, \geq 2$ Systemic Inflammatory Response Syndrome (SIRS) criteria, and CRB-65 score $\geq 2$. Areas under the curve (AUCs) for the clinical risk scores were compared using DeLong's test.

Results: In total, 66 patients (mean age 67.9 years) were included. Of these, 23\% developed severe disease. In-hospital mortality was $20 \%$. Tachypnoea, hypoxemia and confusion at admission were more common in patients developing severe disease. A NEWS2 score $\geq 6$ at admission predicted severe disease with $80.0 \%$ sensitivity and $84.3 \%$ specificity (Area Under the Curve (AUC) $0.822,95 \% \mathrm{Cl} 0.690-0.953$ ). NEWS2 was superior to qSOFA score $\geq 2$ (AUC 0.624, 95\% Cl $0.446-0.810, p<0.05$ ) and other clinical risk scores for this purpose.
\end{abstract}

Conclusion: NEWS2 score at hospital admission predicted severe disease and in-hospital mortality, and was superior to other widely used clinical risk scores in patients with covid-19.

Keywords: Covid-19, Coronavirus, qSOFA, NEWS2, Emergency department, Sensitivity, In-hospital mortality

\footnotetext{
* Correspondence: marius.myrstad@vestreviken.no

'Department of Internal Medicine, Bærum Hospital Vestre Viken Hospital Trust, N-1346 Gjettum, Norway

${ }^{2}$ Department of Medical Research, Bærum Hospital Vestre Viken Hospital Trust, N-1346 Gjettum, Norway

Full list of author information is available at the end of the article
}

(c) The Author(s). 2020 Open Access This article is licensed under a Creative Commons Attribution 4.0 International License, which permits use, sharing, adaptation, distribution and reproduction in any medium or format, as long as you give appropriate credit to the original author(s) and the source, provide a link to the Creative Commons licence, and indicate if changes were made. The images or other third party material in this article are included in the article's Creative Commons licence, unless indicated otherwise in a credit line to the material. If material is not included in the article's Creative Commons licence and your intended use is not permitted by statutory regulation or exceeds the permitted use, you will need to obtain permission directly from the copyright holder. To view a copy of this licence, visit http://creativecommons.org/licenses/by/4.0/ The Creative Commons Public Domain Dedication waiver (http://creativecommons.org/publicdomain/zero/1.0/) applies to the data made available in this article, unless otherwise stated in a credit line to the data. 


\section{Background}

The coronavirus disease 2019 (Covid-19) pandemic is straining health care systems worldwide. As of April 27th, 2020, more than 2,9 million confirmed cases and more than 200,000 deaths have been reported [1]. In Norway, the first case was reported on February 26th, 2020, and the cumulative incidence of reported cases has now reached 138 per 100,000 inhabitants, lower than the hardest affected countries in Europe [2].

The magnitude of the Covid-19 pandemic threatens the capacity and workflow of emergency departments (EDs) and intensive care units (ICU) in hospitals worldwide. Extra strain is imposed by limited knowledge of factors contributing to increased disease severity, and the significant proportion of hospitalised covid-19 patients that require respiratory support. Reports from the US and China, as well as European surveillance data, indicate that approximately $15-20 \%$ of hospitalised patients develop severe disease, defined as fatal outcome or a need for ICU treatment [2-4]. Traditional clinical risk stratification tools are widely used for triage and continuous assessment of patients with severe infectious disease, but few studies have evaluated the use of these tools in patients with SARS-CoV-2 infection. To overcome the challenges faced by the EDs during the pandemic, there is an urgent need for tools to efficiently identify patients at risk of severe disease, and thus help guide decision-making. The National Early Warning Score 2 (NEWS2), the quick Sequential Organ Failure Assessment (qSOFA), Systemic Inflammatory Response Syndrome (SIRS) criteria and CRB-65 are among the most commonly used clinical risk scores, but so far, there is a lack of evidence supporting their use in covid19 patients [5]. We are not aware of any studies that have evaluated the ability of NEWS2 scoring at admission to predict outcome in patients hospitalised with SARS-CoV-2 infection.

\section{Methods}

The aim of this study was to assess and compare the performance of NEWS2 and other commonly used clinical risk scores at ED admission to predict the development of severe disease and in-hospital mortality in patients with covid-19.

This is a prospective cohort study carried out at Bærum Hospital Vestre Viken Hospital Trust, a nonuniversity hospital in the south-eastern part of Norway. The hospital serves approximately 185,000 inhabitants in two municipalities with more than 11,000 ED admissions per year. During the first weeks of the covid-19 outbreak in Norway, Bærum Hospital was among the hospitals in Norway with the highest rate of admission of covid-19 patients. The methods of the study and preliminary data have been previously published [6].

\section{Study population}

Patients admitted to the ED and with confirmed covid19 infection from March 9th 2020 were consecutively included in the study. Patients that were discharged or deceased up until April 27 2020 were included in the current analysis. Covid-19 was confirmed by qualitative detection of nucleic acid from SARS-CoV-2 in throat or nasal secretions by use of real-time polymerase chain reaction [7]. Patients with confirmed infection who were admitted for other reasons and did not have any symptoms or signs of covid-19 infection were excluded from the analysis based on clinical judgement.

\section{Measures and definitions}

The first author registered all data used in this analysis by review of clinical scoring charts and patient records. Clinical scores were based on the first recorded vital signs after admission, documented on charts or in the records.

NEWS2 is a standardised clinical scoring system developed to improve detection of deterioration in acutely ill patients (Fig. 1) [8]. It is based on aggregate scoring of six physiological parameters; respiratory rate, oxygen saturation, systolic blood pressure, pulse rate, level of consciousness or new confusion, and body temperature. In addition, two points are added for patients requiring supplementary oxygen treatment. A NEWS2 score of 5 or 6 is considered a key threshold that may indicate clinical deterioration and should prompt urgent response by a clinician or a team with competence in assessment and treatment of acutely ill patients [8]. The NEWS2 scoring chart is utilised as part of routine patient care practice at our hospital.

qSOFA has been recommended as the tool of choice to assess organ dysfunction in patients with suspected sepsis [9]. Three clinical variables: altered mental status, systolic blood pressure $\leq 100 \mathrm{mmHg}$, and respiratory rate of $\geq 22 / \mathrm{min}$; are scored with one point each. A qSOFA sum score $\geq 2$ should prompt clinicians to investigate for organ dysfunction, initiate or escalate therapy, and to consider increased monitoring or referral to an ICU.

SIRS was defined as an evident infection with the presence of two or more of the criteria temperature $>38^{\circ} \mathrm{C}$ or $<36^{\circ} \mathrm{C}$, heart rate $>90$, respiratory rate $>20$ or $\mathrm{PaCO}_{2}<32 \mathrm{mmHg}$, and white blood cells $>12,000 / \mathrm{mm}^{3}$ or $<4000 / \mathrm{mm}^{3}$ at admission [10].

$C R B-65$ is a clinical score developed for risk stratification of patients with community-acquired pneumonia. One point each is given for the clinical variables new confusion, respiratory rate $\geq 30$, and systolic blood pressure $<90 \mathrm{mmHg}$ or diastolic blood pressure $\leq 60$ $\mathrm{mmHg}$. In addition, age $\geq 65$ years is scored with one point. A score of two or more indicates a need for hospitalisation and in-patient management [11]. 


\begin{tabular}{|c|c|c|c|c|c|c|c|}
\hline $\begin{array}{l}\text { Physiological } \\
\text { paramete } r\end{array}$ & 3 & 2 & 1 & $\begin{array}{l}\text { Score } \\
0\end{array}$ & 1 & 2 & 3 \\
\hline $\begin{array}{l}\text { Respiration rate } \\
\text { (per minute) }\end{array}$ & $\leq 8$ & & $9-11$ & $12-20$ & & $21-24$ & $\geq 25$ \\
\hline $\mathrm{SpO}_{2}$ Scale $1(\%)$ & $\leq 91$ & $92-93$ & $94-95$ & $\geq 96$ & & & \\
\hline $\mathrm{SpO}_{2}$ Scale $2(\%)$ & $\leq 83$ & $84-85$ & $86-87$ & $\begin{aligned} & 88-92 \\
\geq & 93 \text { on air }\end{aligned}$ & $\begin{array}{l}\text { 93-94 on } \\
\text { oxygen }\end{array}$ & $\begin{array}{c}\text { 95-96 on } \\
\text { oxygen }\end{array}$ & $\begin{array}{l}\geq 97 \text { on } \\
\text { oxygen }\end{array}$ \\
\hline Air or oxygen? & & Oxygen & & Air & & & \\
\hline $\begin{array}{l}\text { Systolic blood } \\
\text { pressure }(\mathrm{mmHg})\end{array}$ & $\leq 90$ & $91-100$ & $101-110$ & $111-219$ & & & $\geq 220$ \\
\hline Pulse (per minute) & $\leq 40$ & & $41-50$ & $51-90$ & $91-110$ & $111-130$ & $\geq 131$ \\
\hline Consciousness & & & & Alert & & & CVPU \\
\hline Temperature $\left({ }^{\circ} \mathrm{C}\right)$ & $\leq 35.0$ & & $35.1-36.0$ & $36.1-38.0$ & $38.1-39.0$ & $\geq 39.1$ & \\
\hline
\end{tabular}

National Early Warning Score (NEWS) 2

(c) Royal College of Physicians 2017

Fig. 1 The NEWS2 scoring system. Reproduced from: Royal College of Physicians. National Early Warning Score (NEWS) 2: Standardising the assessment of acute-illness severity in the NHS. Updated report of a working party. London: RCP, 2017

We defined severe disease as a composite measure of death during hospitalization or ICU treatment for any reason during the hospital stay. In-hospital mortality was defined as death during hospital stay for any reason, related or unrelated to the covid-19 infection.

We used the Charlson Charlson Comorbidity Index (CCI) and the Clinical Frailty Scale (CFS) to characterise the premorbid status of the study population. $\mathrm{CCI}$ assesses chronic comorbidities such as heart failure, chronic kidney disease, chronic obstructive pulmonary disease (COPD) and malignancy, and predicts mortality in hospitalised patients [12]. CCI was scored based on comorbidities documented in patient records. CFS is a tool that is used to rapidly summarise the overall level of fitness or frailty based on the functional capacity of the patient 14days prior to the onset of acute illness [13]. CFS was scored based on information about the patients functional status documented in hospital records. Body mass index (BMI) was calculated based on patient height and weight registered during the hospital stay. Smoking habits were self-reported at admission.

\section{Statistical methods}

We used the registry tool EpiData entry client version 4.4.3.1 (The EpiData Association, Odense, Denmark). Continuous variables are presented as the mean \pm standard deviation and categorical variables as the number (\%). We used Student's t test for means of continuous variables and Pearson's Chi-square test of independence for categorical variables to compare characteristics of patient subgroups. Data was missing on smoking for six patients and BMI for 17 patients. To assess the ability of clinical tools to predict severe disease and in-hospital mortality, we calculated sensitivity, specificity, and positive and negative predictive values with 95\% confidence intervals (CIs) using MEDCALC statistical software (http://www.medcalc.org). We used cut-off values that are recommended and commonly used; NEWS2 scores $\geq 5$ and $\geq 6$, qSOFA score $\geq 2$, $\geq 2$ SIRS criteria, and CRB65 score $\geq 2$. Areas under the curve (AUCs) for the clinical risk scores were compared using DeLong's test implemented in the $\mathrm{R}$ package pROC ( $\mathrm{R}$ version 3.6.1, The $\mathrm{R}$ Foundation) [14]. All other statistical analyses 
were conducted using SPSS version 25.0 (IBM, Armonk, NY, USA).

\section{Patient and public involvement}

Patient or public involvement in the design, execution or dissemination of results of the present study was not considered feasible or relevant.

\section{Ethical considerations}

The study was approved by the Vestre Viken Hospital Trust institutional review. Since only routine clinical data were collected from the electronic health records, the requirement for informed consent was waived. A letter with information about the study was sent by post to all patients, allowing the patient to withdraw their data. The study complies with the Declaration of Helsinki. Due to the proximity to real time, the interests of protection of privacy and the uncertainty implicit in a limited dataset, we refrained from detailed characterization of deceased patients, and analysed patients with severe disease and deceased patients as one category.

\section{Results}

During 50 days, from March 9th until April 27th, 75 patients were included in the study. Seven patients who were still under treatment, and two patients with positive SARS-CoV-2 test, but without any symptoms or signs of clinically relevant covid-19 infection, were excluded, leaving 66 eligible patients for the current analysis.

The mean age was 67.9 (median 71.5, range 30-95) years, 38 out of 66 patients (58\%) were men. A total of 15 patients $(23 \%)$ were aged $\geq 80$ years, $19(29 \%)$ had a CFS score $\geq 5$, indicating frailty. Mean CCI was 3.5 , and the most common co-morbidities were hypertension and cardiac conditions.

Fifteen patients (23\%) had severe disease, and inhospital mortality was 20\% (13 out of 66 patients). Seven patients were treated in the ICU, five out of seven patients were transferred to the ICU within $24 \mathrm{~h}$ after hospital admission. Median number of days from admission to transfer to ICU or death was five (mean 5.5 days). Table 1 shows patient characteristics by disease severity. Patients with severe disease were older, had a higher mean CCI, and were more likely to be men and have COPD than patients with less severe disease. Patients with severe disease more often presented with newly onset confusion and dyspnoea at admission.

In total, 28 patients (42\%) had a NEWS2 score $\geq 5$ and 20 (30\%) had a NEWS2 score $\geq 6$ at admission. Only five patients $(8 \%)$ presented with a qSOFA score $\geq 2$. Table 2 shows vital signs and clinical risk scores at admission by disease severity. Table 3 and Fig. 2 shows the performance of the studied clinical risk scores to predict severe disease. The highest AUC was found for a NEWS2 score $\geq 6$. NEWS $2 \geq 6$ also predicted in-hospital mortality with the highest AUC $(0.790,95 \%$ CI $0.643-0.937)$, with 76.9\% (95\% CI 46.2-94.7) sensitivity and 80.1\% (95\% CI 68.0-90.6) specificity (Additional file 1). NEWS2 was superior to qSOFA and other clinical risk scores to predict severe disease (Additional file 2).

\section{Discussion}

The principal finding of the current study is that a NEWS2 score at hospital admission appears superior to qSOFA and other widely used clinical risk scores in prediction of severe disease and in-hospital mortality from covid-19. The high proportion with severe disease among hospitalised patients and the in-hospital mortality of $20 \%$ is in line with recently published reports from other settings $[2-4,15]$.

In the current pandemic situation, early identification of patients at risk of severe disease, and decision of inhospital level of care, is crucial. NEWS2 is widely used in clinical practice, but its use in the context of covid-19 has so far not been evaluated. A Chinese group suggested an adapted version of the NEWS2 score with the addition of age $>65$ years ( 3 points), reflecting evidence that increased age is associated with poor prognosis [16]. Respiratory failure is a hallmark in covid-19 patients, often without accompanying circulatory failure [3]. Several case reports have described the presence of hypoxemia without evident symptoms of respiratory distress, so-called 'silent hypoxemia' [17, 18]. An advantage of NEWS2 compared to the other studied tools is that both hypoxemia and supportive oxygen treatment are included as scoring parameters. In spite of a lack of evidence, the UK Royal College of Physicians recommends the use of the NEWS2 in the management of covid-19, but stresses the fact that any increase in oxygen requirements should trigger further evaluation [19]. Of note, increased oxygen requirement may not be reflected in the NEWS2 score, in which oxygen supplementation is only a binary variable (yes/no).

Larger studies are needed to confirm the results of our study, and to investigate the optimal cut-off value for clinical use. Only 2 of 15 patients who developed severe disease had a NEWS2 score lower than 5 at admission. Both these patients were aged $>75$ years and died during the hospital stay, without ICU treatment. Elderly patients present with less typical and less pronounced symptoms than younger, and clinical risk scores should be used with caution in these patients. While the clinical scores in our study were based on the first recorded signs after ED admission, a recently published case series of 17 patients aged $\geq 80$ years suggest that the variability in NEWS2 scores rather than a single observation at admission could predict poor outcome [20]. 
Table 1 Characteristics and symptoms at admission in hospitalised patients with covid-19 admitted in the period from March 9th to April 27 th 2020 by disease severity, $n=66$

\begin{tabular}{|c|c|c|c|}
\hline & $\begin{array}{l}\text { Severe disease } \\
(\boldsymbol{n}=15)\end{array}$ & Less severe disease $(\boldsymbol{n}=51)$ & $\boldsymbol{p}$-value \\
\hline & Mean (SD) & Mean (SD) & \\
\hline Age (years) & $75.8(13.6)$ & $65.6(16.4)$ & $<0.05$ \\
\hline Clinical Frailty Scale score $^{1}$ & $3.7(2.4)$ & $3.0(2.0)$ & 0.31 \\
\hline Charlson Comorbidity Index & $5.3(3.9)$ & $2.9(2.5)$ & $<0.05$ \\
\hline Body mass index (kilograms $\left./ \mathrm{m}^{2}\right)^{2}$ & $23.4(4.2)$ & $26.3(4.2)$ & 0.09 \\
\hline \multirow[t]{2}{*}{ Days of symptoms prior to admission } & $6.9(3.8)$ & $8.7(5.0)$ & 0.15 \\
\hline & n (\%) & n (\%) & \\
\hline Male gender & $12(80)$ & $26(51)$ & $<0.05$ \\
\hline Admitted from nursing home & $2(13)$ & $2(4)$ & 0.31 \\
\hline Current or previous smoking ${ }^{3}$ & $4(27)$ & $14(33)$ & 0.67 \\
\hline Clinical Frailty Scale score & & & 0.10 \\
\hline $1-2$ (fit) & $7(47)$ & $24(47)$ & \\
\hline 3-4 (managing well or vulnerable) & $1(7)$ & $15(29)$ & \\
\hline$\geq 5$ (moderately or severely frail) & $7(47)$ & $12(24)$ & \\
\hline Charlson Comorbidity Index & & & 0.10 \\
\hline $0-2$ & $3(20)$ & $25(49)$ & \\
\hline $3-5$ & $7(47)$ & $18(35)$ & \\
\hline$>5$ & $5(33)$ & $8(16)$ & \\
\hline \multicolumn{4}{|l|}{ Co-morbidities } \\
\hline Hypertension & $4(27)$ & $15(29)$ & 0.84 \\
\hline Diabetes mellitus & $3(20)$ & $5(10)$ & 0.36 \\
\hline Cardiac conditions & $3(20)$ & $8(16)$ & 0.69 \\
\hline Chronic kidney disease & $2(13)$ & $5(10)$ & 0.70 \\
\hline Malignancy & $3(20)$ & $6(12)$ & 0.41 \\
\hline Asthma & $0(0)$ & $7(14)$ & 0.13 \\
\hline $\mathrm{COPD}^{4}$ & $4(27)$ & $1(2)$ & $<0.05$ \\
\hline Others & $2(13)$ & $9(18)$ & 0.69 \\
\hline \multicolumn{4}{|l|}{ Symptoms } \\
\hline Cough & $8(53)$ & $32(63)$ & 0.51 \\
\hline Dyspnoea & $13(87)$ & $30(59)$ & $<0.05$ \\
\hline Fever & $10(67)$ & $36(71)$ & 0.77 \\
\hline Reduced general condition & $14(93)$ & $39(76)$ & 0.15 \\
\hline New confusion & $5(33)$ & $6(12)$ & $<0.05$ \\
\hline Gastrointestinal & $5(33)$ & $9(18)$ & 0.19 \\
\hline Others & $1(7)$ & $21(41)$ & $<0.05$ \\
\hline
\end{tabular}

${ }^{1}$ Based on functional status 14 days prior to acute illness. ${ }^{2}$ Missing data for 17 patients ( 6 with severe illness and 11 with less severe illness). ${ }^{3}$ Missing data for 8 patients with less severe illness. ${ }^{4}$ Chronic obstructive pulmonary disease

Our study indicates that qSOFA, CRB-65 and SIRS criteria at admission are less able to predict severe disease in patients with covid-19. Thus, these clinical risk scores should be applied with great care in the evaluation of covid-19 patient, and with increased awareness of other clinical signs, in particular signs of respiratory distress and hypoxemia.

\section{Strengths and limitations}

The current study has limitations, the small study size being the most prominent. Furthermore, a single time point clinical evaluation directly after admission allows only a snapshot of the patient's disease course. Patients with severe disease might have been more severely ill already at admission, for instance due to 
Table 2 Vital signs and clinical risk scores at emergency department admission in patients with covid-19 infection in the period from March 9th to April 27th by disease severity, $n=66$

\begin{tabular}{|c|c|c|c|}
\hline & $\begin{array}{l}\text { Severe disease } \\
(n=15)\end{array}$ & Less severe disease $(n=51)$ & $p$-value \\
\hline & Mean (SD) & Mean (SD) & \\
\hline \multicolumn{4}{|l|}{ Vital signs } \\
\hline Body temperature $\left({ }^{\circ} \mathrm{C}\right)$ & $38.0(0.8)$ & $38.0(0.7)$ & 0.99 \\
\hline Respiratory rate (breaths/min) & $26.3(6.3)$ & $20.1(3.3)$ & $<0.05$ \\
\hline Oxygen saturation (\%) & $92.2(3.0)$ & $95.7(2.7)$ & $<0.05$ \\
\hline Heart rate (beats/min) & $89.1(14.7)$ & $80.3(18.2)$ & 0.07 \\
\hline Systolic blood pressure (mmHg) & $127.7(21.5)$ & $132.1(19.8)$ & 0.49 \\
\hline \multirow[t]{2}{*}{ NEWS2 ${ }^{1}$ score } & $6.9(3.2)$ & $3.4(2.3)$ & $<0.05$ \\
\hline & n (\%) & n (\%) & \\
\hline \multicolumn{4}{|l|}{ Clinical risk scores } \\
\hline NEWS2 ${ }^{1}$ score $\geq 5$ & $13(87)$ & $15(29)$ & $<0.05$ \\
\hline NEWS2 ${ }^{1}$ score $\geq 6$ & $12(80)$ & $8(16)$ & $<0.05$ \\
\hline $\mathrm{qSOFA}^{2}$ score $\geq 2$ & $4(27)$ & $1(2)$ & $<0.05$ \\
\hline$\geq 2 \mathrm{SIRS}^{3}$ criteria & $9(60)$ & $17(33)$ & 0.06 \\
\hline CRB-65 score $\geq 2$ & $4(27)$ & $5(10)$ & 0.09 \\
\hline \multicolumn{4}{|l|}{ Selected subscores } \\
\hline Oxygen saturation $\leq 93 \%$ & $9(60)$ & $9(18)$ & $<0.05$ \\
\hline Respiratory rate $\geq 22 / \mathrm{min}$ & $11(73)$ & $15(29)$ & $<0.05$ \\
\hline Systolic blood pressure $\leq 100 \mathrm{mmHg}$ & $1(7)$ & $1(2)$ & 0.35 \\
\hline Heart rate $>90$ beats/min & $5(33)$ & $10(20)$ & 0.27 \\
\hline Acute confusion & $5(33)$ & $7(14)$ & 0.08 \\
\hline Glasgow Coma Scale score $\leq 14$ & $4(27)$ & $3(6)$ & $<0.05$ \\
\hline
\end{tabular}

${ }^{1}$ National Early Warning Score. ${ }^{2}$ Quick Sequential Organ Failure Assessment. ${ }^{3}$ Systemic Inflammatory Response Syndrome

patient delay. However, the mean number of days with symptoms before admission did not differ between patients with severe and less severe disease. Our results may be considered preliminary, providing a strong case for further studies evaluating the ability of NEWS2 to predict poor outcomes in hospitalised patients with covid-19. Studies evaluating NEWS2 at admission and follow-up should be performed in larger prospective cohorts. Furthermore, data on height, weight, comorbidity and frailty were collected retrospectively based on information from hospital records. Missing data for BMI limits the ability of the study to evaluate the role of overweight to predict severe disease.

Main strengths of the study are that we have consecutively included all covid-19 patients admitted from the start of the outbreak, and that our data on vital signs at hospital admission, including all components of the NEWS2 score, are complete.

Table 3 Performance of clinical risk scores at emergency department admission to predict severe disease from covid-19, $\mathrm{n}=66$

\begin{tabular}{llllll} 
& $\begin{array}{l}\text { Sensitivity \% } \\
(95 \% \mathrm{Cl})\end{array}$ & $\begin{array}{l}\text { Specificity \% } \\
(95 \% \mathrm{Cl})\end{array}$ & $\begin{array}{l}\text { PPV \% } \\
(95 \% \mathrm{Cl})\end{array}$ & $\begin{array}{l}\text { NPV \% } \\
(95 \% \mathrm{Cl})\end{array}$ & $\begin{array}{l}\text { AUC } \\
(95 \% \mathrm{Cl})\end{array}$ \\
\hline NEWS2 $\geq \mathbf{5}$ & $86.7(59.5-98.3)$ & $70.6(56.2-82.5)$ & $46.4(35.2-58.1)$ & $94.7(83.0-98.5)$ & $0.786(0.659-0.913)$ \\
NEWS2 $\geq \mathbf{6}$ & $80.0(52.9-95.7)$ & $84.3(71.4-92.9)$ & $60.0(43.1-74.8)$ & $93.5(83.8-97.5)$ & $0.822(0.690-0.953)$ \\
qSOFA $\geq \mathbf{2}$ & $26.7(7.8-55.1)$ & $98.0(89.6-100.0)$ & $80.0(32.6-97.1)$ & $82.0(77.0-86.1)$ & $0.624(0.446-0.810)$ \\
$\geq \mathbf{2}$ SIRS criteria & $60.0(32.3-83.7)$ & $66.7(52.1-79.2)$ & $34.6(23.1-48.3)$ & $85.0(74.8-91.6)$ & $0.633(0.470-0.796)$ \\
CRB-65 $\geq \mathbf{2}$ & $26.7(7.8-55.1)$ & $90.2(78.6-96.7)$ & $44.4(19.7-72.3)$ & $80.7(75.3-85.2)$ & $0.584(0.410-0.759)$ \\
\hline
\end{tabular}




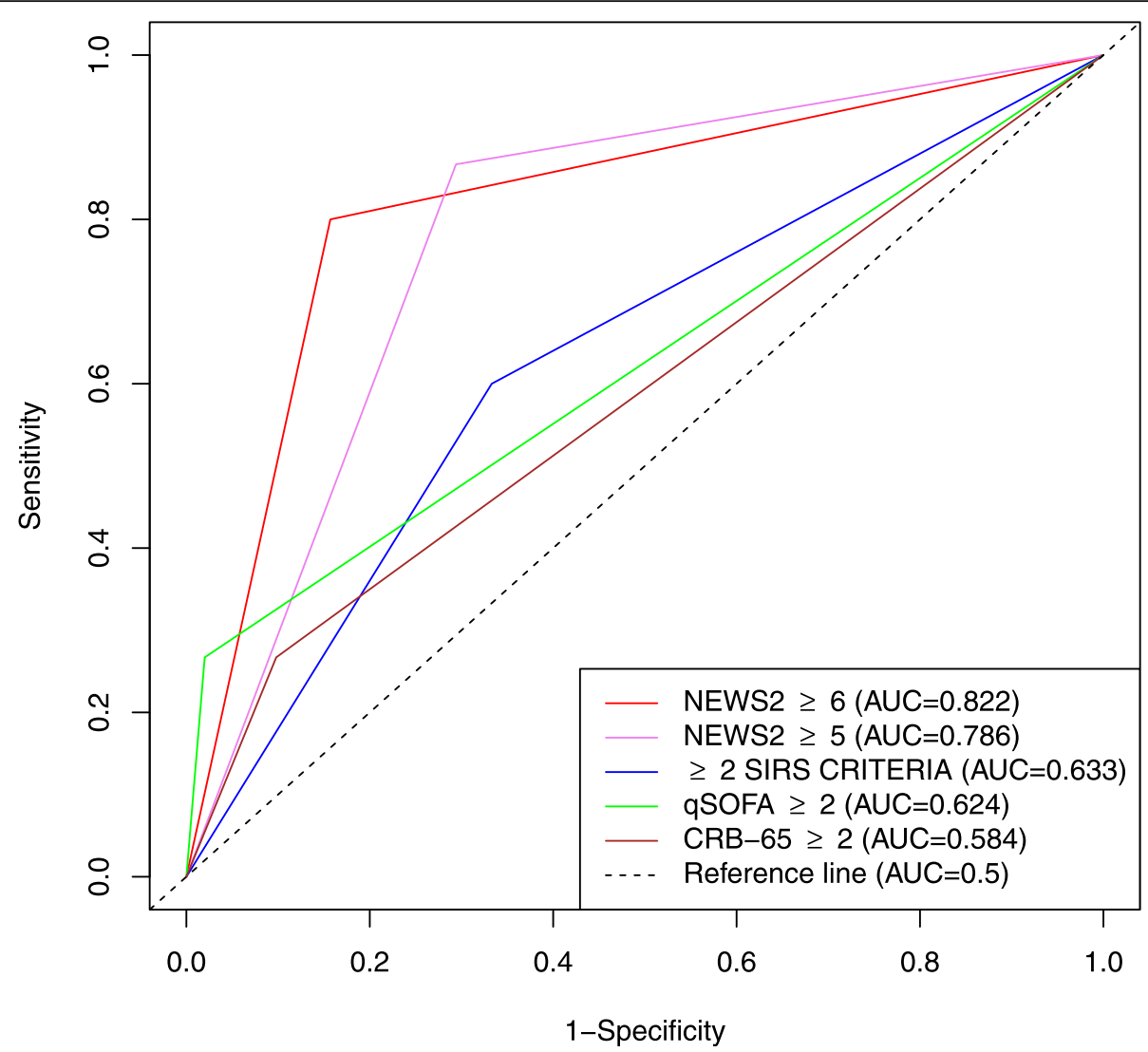

Fig. 2 Receiver Operator Characteristic curves illustrating the ability of NEWS2 scores $\geq 5$ and $\geq 6$, and qSOFA score $\geq 2$, CRB- 65 score $\geq 2$ and $\geq 2$ SIRS criteria at emergency department admission to predict severe disease from covid-19, $n=66$

\section{Conclusions}

One out of four patients hospitalised with covid-19 had severe disease, and in-hospital mortality was $20 \%$. NEWS2 score at emergency department admission predicted severe disease and in-hospital mortality and was superior to qSOFA and other clinical risk scores for this purpose. A NEWS2 score $\geq 6$ predicted severe disease with $80.0 \%$ sensitivity and $84.3 \%$ specificity. The use of clinical scoring systems to predict severe disease and mortality in patients with covid-19 should be investigated further in larger prospective studies.

\section{Supplementary information}

Supplementary information accompanies this paper at https://doi.org/10. 1186/s13049-020-00764-3.

Additional file 1 Table S1. Performance of clinical risk scores at emergency department admission to predict in hospital mortality in patients with covid-19, $n=66$.

Additional file $\mathbf{2}$ Table S2. Comparison of the areas under receiver operating characteristic curves for the ability of clinical risk scores to predict severe disease and in-hospital mortality from covid-19.

\section{Acknowledgements \\ None.}

\section{Authors' contributions}

$M M, T B, A A T$ and ELA contributed to data collection. MM and SN were responsible for the statistical analyses. MM, AAT and TB drafted the manuscript. All authors reviewed and revised the manuscript. The corresponding author attests that all listed authors meet authorship criteria and that no others meeting the criteria have been omitted. The author(s) read and approved the final manuscript.

\section{Funding}

The current work did not receive any funding. All authors are employees at Vestre Viken Hospital Trust.

\section{Availability of data and materials}

The datasets generated and/or analysed during the current study are not publicly available, but are available from the corresponding author on reasonable request.

\section{Ethics approval and consent to participate}

The Hospital Trust institutional review board approved the study as minimal risk as only routine clinical data were collected from the electronic health records. Hence, the requirement for informed consent was waived. However, a letter with information about the study was sent by post to all patients, enabling the patient to withdraw their data. 


\section{Consent for publication}

The publication of the results from this study was approved by the The Hospital Trust institutional review board.

\section{Competing interests}

MM and HIH have received a speaker fee from Boheringer-Ingelheim. The other authors declare that they have no competing interests.

\section{Author details}

'Department of Internal Medicine, Bærum Hospital Vestre Viken Hospital Trust, N-1346 Gjettum, Norway. ${ }^{2}$ Department of Medical Research, Bærum Hospital Vestre Viken Hospital Trust, N-1346 Gjettum, Norway. ${ }^{3}$ K.G. Jebsen Centre for B cell malignancies, Department of Immunology and Transfusion Medicine, Oslo University Hospital, N-0372 Oslo, Norway. ${ }^{4}$ Department of Informatics, University of Oslo, N-0316 Oslo, Norway. ${ }^{5}$ Oslo Center for Biostatistics and Epidemiology, Oslo University Hospital and University of Oslo, N-0317 Oslo, Norway. ${ }^{6}$ Institute of Clinical Medicine, University of Oslo, N-0316 Oslo, Norway.

Received: 19 May 2020 Accepted: 7 July 2020

Published online: 13 July 2020

\section{References}

1. European Centre for Disease Prevention and Control - An agency of the European Union webpage: https://www.ecdc.europa.eu/en accessed $27 \mathrm{Apr}$ 2020.

2. Coronavirus disease 2019 (COVID-19) in the EU/EEA and the UK - ninth update, 23 April 2020 [Report]. Stockholm, 2020: European Centre for Disease Prevention and Control; 2020 [Available from: https://www.ecdc. europa.eu/sites/default/files/documents/covid-19-rapid-risk-assessmentcoronavirus-disease-2019-ninth-update-23-april-2020.pdf.

3. Richardson S, Hirsch JS, Narasimhan M, Crawford JM, MCGinn T, Davidson $\mathrm{KW}$, et al. Presenting characteristics, comorbidities, and outcomes among 5700 patients hospitalized with COVID-19 in the New York City area. JAMA. 2020. https://doi.org/10.1001/jama.2020.6775.

4. Wu Z, McGoogan JM. Characteristics of and important lessons from the coronavirus disease 2019 (COVID-19) outbreak in China: summary of a report of 72314 cases from the Chinese Center for Disease Control and Prevention. JAMA. 2020. https://doi.org/10.1001/jama.2020.2648.

5. Sperrin M, Grant SW, Peek N. Prediction models for diagnosis and prognosis in Covid-19. BMJ. 2020;369:m1464. https://doi.org/10.1136/bmj.m1464.

6. Ihle-Hansen $\mathrm{H}$, Berge $\mathrm{T}$, Tveita A, Ernø PE, Andersen EL, Wang CH, et al. COVID-19: symptoms, course of illness and use of clinical scoring systems for the first 42 patients admitted to a Norwegian local hospital. Tidsskr Nor Legeforen. 2020. https://doi.org/10.4045/tidsskr.20.0301.

7. Corman VM, Landt O, Kaiser M, Molenkamp R, Meijer A, Chu DK, et al. Detection of 2019 novel coronavirus (2019-nCoV) by real-time RT-PCR. Euro Surveill. 2020;25(3). https://doi.org/10.2807/1560-7917.Es.2020.25.3.2000045.

8. Physicians RCo. National Early Warning Score (NEWS) 2: Standardising the assessment of acute-illness severity in the NHS. Updated report of a working party. London: RCP, 20172017 [Available from: https://www. rcplondon.ac.uk/projects/outputs/national-early-warning-score-news-2 accessed 24 Apr 2020.

9. Singer M, Deutschman CS, Seymour CW, Shankar-Hari M, Annane D, Bauer $M$, et al. The Third International Consensus Definitions for Sepsis and Septic Shock (Sepsis-3). JAMA. 2016;315(8). https://doi.org/10.1001/jama.2016.0287.

10. American College of Chest Physicians/Society of Critical Care Medicine Consensus Conference. Definitions for sepsis and organ failure and guidelines for the use of innovative therapies in sepsis. Critical care med. 1992;20(6):864-74.

11. Lim WS, van der Eerden MM, Laing R, Boersma WG, Karalus N, Town Gl, et al. Defining community acquired pneumonia severity on presentation to hospital: an international derivation and validation study. Thorax. 2003;58(5). https://doi.org/10.1136/thorax.58.5.377.

12. Charlson ME, Pompei $P$, Ales $\mathrm{KL}$, Mackenzie $C R$. A new method of classifying prognostic comorbidity in longitudinal studies: development and validation. J Chronic Dis. 1987;40(5). https://doi.org/10.1016/00219681(87)90171-8.

13. Rockwood K, Song X, Macknight C, Bergman H, Hogan DB, McDowell I, et al. A global clinical measure of fitness and frailty in elderly people. CMAJ. 2005;173(5). https://doi.org/10.1503/cmaj.050051.
14. DeLong ER, DeLong DM, Clarke-Pearson DL. Comparing the areas under two or more correlated receiver operating characteristic curves: a nonparametric approach. Biometrics. 1988;44(3):837-45.

15. Chen T, Wu D, Chen H, Yan W, Yang D, Chen G, et al. Clinical characteristics of 113 deceased patients with coronavirus disease 2019: retrospective study. BMJ. 2020;368:m1091. https://doi.org/10.1136/bmj.m1091.

16. Liao X, Wang B, Kang Y. Novel coronavirus infection during the 2019-2020 epidemic: preparing intensive care units-the experience in Sichuan Province, China. Intensive Care Med. 2020;46(2). https://doi.org/10.1007/s00134-02005954-2.

17. Xie J, Tong Z, Guan X, Du B, Qiu H, Slutsky A. Critical care crisis and some recommendations during the COVID-19 epidemic in China. Intensive Care Med. 2020. https://doi.org/10.1007/s00134-020-05979-7.

18. Ottestad W, Seim M, Maehlen J. COVID-19 with silent hypoxemia. Tidsskr Nor Laegeforen. 2020. https://doi.org/10.4045/tidsskr.20.0299.

19. NEWS2 and deterioration in COVID-19: Royal College of Physicians; 2020 [Available from: https://www.rcplondon.ac.uk/news/news2-anddeterioration-covid-19 accessed 24 April 2020.

20. Sze S, Pan D, Williams CML, Wong N, Sahota A, Bell D, et al. Letter to the editor: variability but not admission or trends in NEWS2 score predicts clinical outcome in elderly hospitalised patients with COVID-19. J Inf Secur. 2020. https://doi.org/10.1016/j.jinf.2020.05.063.

\section{Publisher's Note}

Springer Nature remains neutral with regard to jurisdictional claims in published maps and institutional affiliations.

\section{Ready to submit your research? Choose BMC and benefit from:}

- fast, convenient online submission

- thorough peer review by experienced researchers in your field

- rapid publication on acceptance

- support for research data, including large and complex data types

- gold Open Access which fosters wider collaboration and increased citations

- maximum visibility for your research: over $100 \mathrm{M}$ website views per year

At BMC, research is always in progress.

Learn more biomedcentral.com/submissions 